\title{
School libraries as power-houses of empathy: People for loan in The Human Library
}

\author{
Deborah Brown \\ Monte Sant' Angelo Mercy College \\ 128 Miller Street, North Sydney, NSW \\ Australia \\ dbrown@monte.nsw.edu.au
}

\begin{abstract}
The capacity of literary fiction to foster the trait of empathy in readers has received significant recent coverage in popular and academic literature (see for example, Gavigan \& Kurtts 2011). School libraries, through their natural connection to storytelling in all its forms, can help foster a culture of empathy and respect, and can play an active role in promoting tolerance within the school community. This paper will focus on the worldwide movement known as The Human Library, which aims to "challenge prejudice through conversation" (Human Library UK 2016a). The Human Library reimagines the concept of a reader opening a book and looking at life through the eyes of 'the other' as they turn the pages, by replacing physical books with 'living books': people from all walks of life who volunteer to be 'borrowed' by a 'reader' for a conversation. Through respectful dialogue, stereotypes can be broken down and empathy can replace stigmatization. This paper will focus on how any school can host a Human Library to build a culture that celebrates, rather than fears, diversity and difference.
\end{abstract}

\section{Keywords}

Empathy, living libraries, discrimination, stereotypes 


\section{Introduction}

What is empathy? In its simplest form, empathy is the ability to imagine what another person might be thinking or feeling. It is often described as the ability to walk a mile in someone else's shoes. In the literary world, Atticus Finch, in To Kill a Mockingbird, said that "You never really understand a person until you consider things from his point of view until you climb into his skin and walk around in it" (Lee 2010, p. 33). This is the embodiment of empathy as it generally understood: the ability to see the world through the eyes of another. But empathy also operates on a deeper cognitive level when it enables us to understand why someone might decide something or act in a certain way irrespective of whether we agree with what they have done or not (Stripling 2012, p. 20).

The school library has many roles and functions in the $21^{\text {st }}$ century. We know that we haven't been simple book repositories for decades. Our continuous existence in the digital age has been a result of the way we respond to a changing world and to the changing needs of our clients. We are makerspaces, media hubs and digital production studios. We are literacy and research centres. But we are so much more than this too. Libraries are places that nurture values and ethics. We promote academic honesty and stewardship of resources. We facilitate knowledge of 'the other' through curating collections of fiction and non-fiction that reflect the diversity of the world. Foust and Ahkmed argue that libraries by the very nature of those who look after them, espouse values "such as freedom of speech and a love of knowledge" that nurture and promote empathy (2014, p. 92). This paper will examine the role of the school library in supporting diversity in the school community; how the school library can play a key role in fostering a culture of empathy and respect amongst students in the school community and, more broadly, between our students and the broader community beyond our school's walls.

Specifically, this paper will discuss how adding human books to your library collection can make your library a power-house of empathy building in your school: how your library can potentially change lives not just through literacy and learning, but through actively facilitating connections and conversations between your students and people they may never have an opportunity to come into contact with in their everyday lives. This is the ethos behind the Human Library: that stereotypes can be shattered, that prejudice can be stripped away and replaced with empathy, through the mechanism of conversation and dialogue.

\section{Fiction fosters empathy}

As librarians, we know the power of a story to transport and transform. As a child I longed to find a wardrobe that I could step into, gently part the hanging fur coats to find a glowing lamppost and a snow covered Narnia-like world. Unfortunately I never literally managed to find that world, but I'm sure we all know the thrill of travelling to other places, other times, through war zones and fantasy worlds through the books we have immersed ourselves in. And we know the thrill of seeing our students view the world through the eyes of someone they are not: a different gender, a different age, a different colour or nationality, a different life. The author of Game of Thrones, George R. R. Martin has been quoted as saying that "a reader lives a thousand lives before he dies. The man who never reads lives only one."

Reading fiction, literary fiction, breeds empathy. What is it like to live in a slum in Calcutta? To have a disfigured face? To be forced into marriage at age ten? For a girl to have to dress as a boy in order to feed one's family? To have a close family member die of cancer? While many of our day-to-day experiences can be influenced by stereotypes and assumptions and by the superficial labels that we use to categorise those we think we have the measure of, the lives of those we meet in literary fiction may "disrupt our expectations", leading us to a greater understanding of others (Comer Kidd \& Castano 2013, p. 378). Author Neil Gaiman says that when you read fiction "you're being someone else, and when you return to your 
own world, you're going to be slightly changed (Gaiman 2013). A number of recent studies have concluded that reading literary fiction fosters the trait of empathy: how we relate to others and recognise the inherent humanity in others, especially in those who may appear to be different to ourselves (see for example, Chiaet 2013; Bergland 2014). There is power in fiction, power in storytelling, to illuminate the unknown, the out of reach, the 'other'.

Globalization, social media and the information explosion have apparently brought the world to our laptops. Or have they? We want our students to be citizens of the world, but we are mindful that in contrast to the perspective that the internet opens our students' eyes to the world's diversity, it is also possible for any person to have their world view narrowed by being exposed to an endless stream of information and invective that simply reinforces strongly held pre-existing beliefs. No matter how obscure or simply incorrect my views might be about a particular group in society or a significant global issue, I will be able to find someone or some organisation online that supports what I think, tells me I am right and reinforces my solipsistic and possibly deeply misguided views. This is why empathy is often touted as the most important $21^{\text {st }}$ century skill: in order to be a truly global community, in order for our students to be effective global leaders and advocates for the rights of all people, they must first be able to identify with the vast diversity of humanity.

\section{Human Libraries}

Which brings me to the Human Library. In the Human Library, instead of borrowing a printed book and experiencing another life through the words on the page, patrons borrow a living book, sit down for a short conversation with them, and see the world through the eyes of someone very different to themselves; someone who they may have preconceived ideas about; someone who they may assume they know; someone who they may stereotype without even being aware of it.

The first Human Library was held at the Roskilde music festival in Denmark in 2000. Now Human Library events are held in more than 70 countries worldwide (Human Library UK, 2016b).

Its roots date back to 1993, when five teenagers, motivated by the violent stabbing of a friend in Copenhagen, created a youth organisation called Stop the Violence. Stop the Violence aimed to reduce youth violence and to counteract the negative stereotyping of Danish youth that had emerged in the media reports of the attack on their friend (Human Library UK, 2016b).

By the year 2000, when Stop the Violence had more than 30,000 members, they were approached by the Roskilde Festival organizers to create an activity that would build positive connections and dialogue between the many different subcultures, some hostile to each other, attending the festival (Human Library UK, 2016b). Roskilde is a massive music festival that attracts music fans from throughout Europe and around the world. That year more than 100,000 people attended the festival. The event that was created was the first Human Library, and it featured over 75 human books (Human Library UK, 2016b).

Since then the movement has grown worldwide. It has been held in Festivals in Ireland and Russia, Universities in Manila, Las Vegas and Poland, Museums in Chicago, Colleges in Kazakhstan and public libraries in Copenhagen (Human Library, 2016b).

I'll now digress for a moment to tell you a little about myself and the school in which I work. I manage the library in a secondary school just on the northern side of Sydney Harbour, Australia. Monte is an independent, Catholic girls' high school, with almost 1200 students. We offer the International Baccalaureate curriculum to our students from years 7 to 12 . Monte is a metropolitan school, located in an affluent business district. The values of our 
school are deeply rooted in social justice, advocacy and recognition of the human dignity inherent in all people. $7 \%$ of our students come from a non-English language background (Australian Curriculum, Assessment and Reporting Authority, 2016). In Sydney, that's a very low percentage, when almost $38 \%$ of people in Sydney speak a language other than English at home (Australian Bureau of Statistics, 2012). Eight years ago our wonderful teacher librarian, Jenny Uther, was looking for a way to facilitate an authentic empathy-building experience for our students: to get them to engage with the world by bringing the world into our school - actually into our school library. She implemented our annual Human Library event, and it is now one of the biggest events on our school library's calendar, with up to twelve living books involved, and more than 120 students borrowing from this precious temporary collection.

\section{Methodology}

So how does it work? The Human Library organisation has established a methodology outlining the best way to run the event. The methodology is based on two principles: inclusion and choice (Human Library UK, 2016c).

Inclusion is enacted in the way that the living books are recruited from all walks of life, from a broad range of backgrounds and experiences. The Human Library is not intended to be used to highlight a single issue or a particular group. By being inclusive, it sends a powerful message that discrimination and stereotyping can be experienced by many different, perhaps unexpected groups in our communities (Human Library UK, 2016c).

The second part of the methodology is about choice, and there are a number of different aspects to this. Patrons of the Human Library, in our case our students, must be given choice over whether or not to participate, over which living book to borrow; choice over the questions they will ask and the conversation they will have with the book they borrow. This is a key tenet of the event and it embodies the idea that while we are trying to break down preconceived assumptions about different people in society, we are extending that to our patrons - making no assumptions about them, why they may choose to participate or not, or why they are choosing to borrow a particular book.

In addition, the books have choices: they choose whether or not to participate, whether to answer a particular question from the borrower, and whether to themselves ask a question of the patron who has borrowed them (Human Library UK, 2016c).

\section{Planning and implementation}

Organizing a Human Library event in a school does take a significant amount of planning and time. I must emphasise that I am lucky to have a library team that is fully committed to organizing and implementing this event.

Planning begins with setting a date for the event, and navigating the many different school calendars in which other faculties have booked events or exams. Finding a date that will not be overly disruptive to our school is key, as we are taking students out of classes and monopolising our library spaces during the event. We run the event for about two hours on the designated day.

One of the key elements of a successful Human Library event is to compile an eclectic collection of living books. This is perhaps the most challenging part of hosting the Human Library in your school. We spend a month or two recruiting our books. We advertise in the school newsletter that goes to parents each week, explaining the concept and asking for people in the extended school community to consider volunteering. We email the staff at the school, asking if they might know someone who would be suitable. We contact organisations 
that represent groups who might have experienced stigmatization or feel side-lined from mainstream society. We also draw on the immediate school community, because we know that there are some amazing people who we cross paths with everyday who are experiencing or have experienced discrimination, or misunderstanding. We are looking for diversity within our collection, and variety from year to year so that we address the many different kinds of prejudices or stigmas that our students may knowingly or unknowingly have.

Some examples of the books we have recruited for our Human Library events include:

- $\quad$ Katie is a Year 9 student at our school. She was born with a profound hearing disability, and received a cochlear implant to enable her to hear when she was just a little girl. A cochlear implant is an electronic device that replaces the function of the damaged part of the inner ear. It's clear from her implant that she has a hearing difficulty and she has been so generous and brave to volunteer her time as a living book in our Human Library twice now, so that other students can find out what it's like to be at school everyday hearing the world differently.

- $\quad$ Rolf has been one of our living books for three years. He lost most of his vision due to the eye condition macular degeneration. With the aid of technology and his beautiful guide dog, Echo, he has adapted to his vision loss.

- $\quad$ Cody is an incredibly charismatic man with professional qualifications in management and human resources. He also lives with the chronic condition cystic fibrosis.

- $\quad$ Sister Jackie is a retired nun, a Sister of Mercy, who spent more than ten years living and working in the shanty towns of Cerro Choclo and Cerro Candela near Lima, Peru to improve the lives of women and children.

- Jo has overcome the eating disorder anorexia nervosa

- $\quad$ Taghred is a mother of four who came to Australia from Lebanon as a small child. She is a Muslim, lives in Sydney and wears here headscarf to work everyday.

- $\quad$ Theresa is an Indigenous Australian woman who grew up among the Worimi people in an aboriginal mission on the North Coast of New South Wales.

- $\quad$ Stephen was diagnosed with the chronic illness multiple sclerosis 15 years ago and now works for the MS Society managing their ambassador program.

- $\quad$ Samantha is a scientist working at the Centre for Hypersonics at the University of Queensland. Her area of speciality is supersonic combustion research, and everyday she challenges stereotypical thinking about women in the world of science.

- $\quad$ Natalie is another of our local heroes, a staff member at our school library, who was born in South Africa and grew up under the Apartheid system of racial segregation. She has first-hand experience of brutal discrimination based simply on the colour of her skin.

- $\quad$ Ella is a young woman who experienced homelessness at the age of 14 .

Common to each of our books is the fact that they have experienced being stereotyped or subject to discrimination at some point in their lives.

As the date of the event draws closer, we start our publicity campaign: promoting and explaining the event to our student body in order to encourage them to participate. We produce a digital slideshow, a 'catalogue' of the books, with a short explanation or 'blurb' about each book, which is shown to students in library classes and English classes. We advertise the event in the daily student newsletter and we ensure that all our teachers know about the event and so can encourage their students to attend. We then request that students who would like to borrow a human book nominate the book they would like to borrow, their preferred time, and register for the event either online using a digital form linked 
from our library website, or using a printed form which we make available at our library loans desk.

Student volunteers from senior years are also recruited to assist us with marshalling and timekeeping on the day. They escort our borrowers to their book, introduce them and discreetly ensure that loans are kept to the 15 minutes allocated time.

We have on average 120 students participating in the Human Library as book borrowers each year. This makes it the largest event of the year on our library calendar. We are keenly aware that some students, particular the younger students, may be nervous or shy about holding a conversation with a person that they do not know, so we allow our students to attend in pairs, or groups up to a maximum of three students.

Dreher and Mowbray write that the safe, comfortable environment of a Human Library event is thought to contribute to a "non-judgemental atmosphere" conducive to open conversations (2012, p. 25). We set our library up on the day somewhat like a café: a table for each book with chairs arranged around it; a printed name label for each of our books and even flowers on the tables. We are trying to cultivate an intimate, personal, somewhat informal environment that feels relaxed but still respectful.

The beauty of the interaction is in its simplicity: having a conversation is something we all, irrespective of our different backgrounds, are familiar with. It is a dialogue between two people, the borrower and the book, who are demonstrating by their very presence that they are open to having their thinking challenged, to sharing something of themselves. Importantly, as Ashmore points out, the interaction between 'reader' and 'book' in the Human Library is a reciprocal transaction in which both participants are sharing and exchanging information (2010, p. 3). In this way the Human Library transcends the metaphor of having 'books' and 'readers', which perhaps falsely implies a one-sided scenario in which a storyteller downloads content to a passive recipient. It is, instead, a genuinely bilateral interaction where participants meet as equals.

\section{Support from senior management}

Within your school, and in your communication with the key decision makers at your school, there are clear benefits in making explicit the link between the Human Library and the broader strategic goals of your school. By drawing connections between your goals for the event and the values underpinning your school, you are demonstrating to key decision makers that your library plays a pivotal role in maintaining and developing the principles for which your school stands. For example, my school has a strategic vision document which outlines six key goals, the first of which concerns continuation of the traditions and values of the school, anchored in a concern for social justice and human dignity. Another goal is to be a leader in $21^{\text {st }}$ Century learning by providing innovative, authentic learning experiences to our students (Monte Sant' Angelo Mercy College, 2012).

In the annual report on library operations that I prepare for senior management each year, I make an explicit connection between the outcomes of the activities we hold and the longterm goals of our school. The Human Library clearly provides an opportunity for our students to engage in immersive, authentic, experiential learning, compatible with the values and ethos of the school. Holding the event creates a strong anchor for us to publicise how the library's role and influence is not limited merely to what goes on within our walls, and is certainly not limited to what you see on our shelves. The broader implication of holding events such as this is that school libraries can have profound, life-long impacts on students beyond providing literacy instruction or technical skills. 


\section{Link to International Baccalaureate values}

As an International Baccalaureate (IB) school that offers both the Middle Years Program and the Diploma Program, we have taken to heart the IB's mission statement to "help create a better and more peaceful world through intercultural understanding and respect" (International Baccalaureate Organisation, 2016). From the time our students enter our school they are encouraged to recognise the common humanity of all people, and to develop the ten attributes known as the IB Learner Profile. In order to be responsible members of their local and global communities students are encouraged to be inquirers, knowledgeable, thinkers, communicators, principled, open-minded, caring, risk-takers, balanced and reflective (International Baccalaureate Organization, 2013). Opportunities to actively nurture and develop these attributes are highly valued by our school, and it is self-evident that students who engage with the Human Library experience are called on to demonstrate many if not all of the learner profile traits. This contributes not only to student development within the IB framework, but provides another compelling reason for the school to support the event year after year.

\section{Evaluation \& feedback}

One of the key elements that we have incorporated into our iteration of the Human Library is a feedback component. Most importantly, we want to get evidence that our goal, which is to foster empathy and challenge stereotyping, is being achieved. What are the students getting out of the experience? Was it what they expected? Would they attend again, or encourage others to attend? Did it change their thinking in any way? The other reason we gather feedback is a little more pragmatic: we want to publicise the work of the library, our initiatives, our achievements, and if we can do this using the voices of the students who benefit from our programs, it adds authenticity to the story that we are telling about our library in our newsletters to parents, in our library annual report, and in our school yearbook.

We have used several different mechanisms to gather student feedback on their experience of the Human Library. In previous years we have invited students to fill out an online form containing some question prompts. More recently however we have been using a class set of iPads connected to our interactive whiteboard, with the Padlet app to create a digital canvas of student comments that are visible to all participants, both the borrowers and the books. Examples of student feedback include:

Sarah was very brave to share her stories and teach us that to overcome something in life takes courage and persistence but will have a positive impact on our lives and future

Today I have really enjoyed being involved in the Human Library. Talking to Rolf was an experience I will never forget. I learnt new things and think that we shouldn't take things for granted because we are not experiencing things in comparison to others. Rolf was very inspiring and I know others will feel the same

Talking to Teresa was really interesting and engaging. Hearing her story was a great experience. It was amazing to hear how different her life as a child was to how her life is now and also how our life is.

\section{Affirmation of books}

A fascinating tangential benefit of holding a Human Library event is that the act of taking part in it as a human book is an affirming experience for participants, and can even be a confidence-building experience for them (Dreher \& Mowbray 2012, p. 45). Our living books 
have expressed to us how being involved makes them feel valued, how they appreciate the opportunity to tell their stories to a willing audience, how they feel they are making an active contribution towards the promotion of tolerance and diversity.

We welcome feedback from our living books, which they can also record on our Padlet wall:

Your questions and interactions were thoughtful, considerate and very enjoyable to engage with. I thoroughly enjoyed my time with you today and hope to see you again next year.

In addition, our living books enjoy the opportunity to interact with each other. We schedule the event with a break in the middle, coinciding with the students' 'recess' (morning tea) break. This gives our guests an opportunity to meet each other informally over coffee, to share stories, discuss the event and simply to chat. In one way it could be said that this is their opportunity to 'borrow' each other.

\section{Conclusion}

Sometimes it is the simplest thing that can profoundly impact on a life. The Human Library leverages the simple act of a conversation to find common ground and understanding between 'book' and 'reader'. Facilitating a respectful conversation between willing participants has the potential to imbue sometimes divisive issues like race, religion or disability with humanity and dignity. Scaffolding the event using metaphors ('book', 'reader') familiar to students that invoke the welcoming intimacy of a library contributes to the culture of openness, honesty and respect that are essential to holding a successful Human Library event.

By openly celebrating and affirming the diversity of the living books who generously consent to being borrowed as part of the Human Library, we are sending a powerful message to the school community that we value and affirm our students' differences as well. Providing access to a library of living books creates a forum to highlight the sometimes insidious nature of discrimination and exclusion, and creates a culture of celebrating, rather than fearing, diversity.

\section{References}

Ashmore, A. (2010). Alive with knowledge: engaging communities through living libraries. Library Student Journal, 5, 14-22.

Australian Bureau of Statistics. (2012). Language spoken at home. Top 20 - Australia. Retrieved May 18, 2016, from http://abs.gov.au/census

Australian Curriculum, Assessment and Reporting Authority. (2016). School profile: Monte Sant' Angelo Mercy College, North Sydney, NSW. Retrieved May 27, 2016, from https://www.myschool.edu.au/SchoolProfile/Index/96407/MonteSantAngeloMercyColl ege/43675/2015

Bergland, C. (2014). Can reading a fictional story make you more empathetic? Retrieved January 27, 2016, from https://www.psychologytoday.com/blog/the-athletesway/201412/can-reading-fictional-story-make-you-more-empathetic 
Chiaet, J. (2013). Novel finding: reading literary fiction improves empathy. Retrieved January 27, 2016, from http://www.scientificamerican.com/article/novel-finding-readingliterary-fiction-improves-empathy/

Comer Kidd, D., \& Castano, E. (2013). Reading literary fiction improves Theory of Mind. Science, 342, 377-380. Retrieved February 13, 2016, from http://science.sciencemag.org/content/342/6156/377

Dreher, T., \& Mowbray, J. (2012). The power of one on one: Human libraries and the challenges of antiracism work (UTS Shopfront Monograph Series No. 7). Broadway, N.S.W.: UTS ePress.

Foust, M., \& Ahkmed, S. (2014). Kindness counts: encouraging empathy in secondary school library programs. International Association of School Librarianship. Selected papers from the annual conference (pp. 91-106). Retrieved February 14, 2016, from http://search.proquest.com/openview/791926747f83858865629949b9abf248/1.pdf?p q-origsite $=$ gscholar $\& \mathrm{cbl}=26551$

Gaiman, N. (2013). The future of reading and libraries. Lecture presented at The Reading Agency, London. Retrieved February 14, 2016, from http://www.theguardian.com/books/2013/oct/15/neil-gaiman-future-libraries-readingdaydreaming

Gavigan, K. W., \& Kurtts, S. (2011). Using children's and young adult literature in teaching acceptance and understanding of individual differences. The Delta Kappa Gamma Bulletin, Winter, 11-16.

Human Library UK. (2016a). Human Library UK. Retrieved May 31, 2016, from http://humanlibraryuk.org/

Human Library UK. (2016b). History. Retrieved February 14, 2016, from http://humanlibraryuk.org/human-library/history/

Human Library UK. (2016c). The Methodology. Retrieved May 26, 2016, from http://humanlibraryuk.org/human-library/the-methodology/

International Baccalaureate Organisation. (2016). Mission. Retrieved May 30, 2016, from http://www.ibo.org/about-the-ib/mission/

International Baccalaureate Organization. (2013). IB Learner Profile. Retrieved May 31, 2016, from http://www.ibo.org/contentassets/fd82f70643ef4086b7d3f292cc214962/learnerprofile-en.pdf

Lee, H. (2010). To kill a mockingbird. London: Arrow.

Monte Sant' Angelo Mercy College. (2012). Monte Sant' Angelo Mercy College: Strategic vision 2012-2020. Retrieved June 2, 2016, from http://www.monte.nsw.edu.au/files/4713/6746/7355/monte_strategic_vision_web_aug ust_2012.pdf

Stripling, B. (2012). Fostering empathy: Who cares? School Library Monthly, 28(4), 20-22.

\section{Biographical note}


Deborah Brown manages the school library at Monte Sant Angelo Mercy College, an independent girls' secondary in Sydney which offers the International Baccalaureate program, a role she has held for four years. She came to the education sector following fifteen years spent in corporate (media) and government (parliament) special libraries. Deborah has a passion for young adult fiction and for the power of storytelling in all its forms to illuminate darkness, inspire action and build connections between people from all walks of life. She has a Bachelor of Applied Science in Information Studies and a Masters in Education from the University of Technology, Sydney. 